DOI https://doi.org/10.18551/rjoas.2018-11.36

\title{
THE TECHNICAL EFFICIENCY ANALYSIS OF RICE FARMING IN DISTRICTS OF SOUTH BORNEO, INDONESIA
}

\author{
Ikhsan Sadik, Azis Yusuf, Salawati Umi \\ Department of Agricultural Economics and Social Sciences, Faculty of Agriculture, \\ Lambung Mangkurat University, Banjarbaru, Indonesia \\ *E-mail: sikhsan@ulm.ac.id
}

\begin{abstract}
The technical efficiency is meant as the ability of a firm to produce maximum output given a set of inputs and available production technology. A firm that had production does not reach maximum level is supposed to be technically inefficient. This research aimed to assess the technical efficiency performance of rice farming in the Sub-District of Cerbon, the District of Barito Kuala and the Sub-Disrict of Aluh-aluh, District of Banjar by employing an econometric model of the stochastic frontier production function. The error structure of stochastic frontier production model made up of two independent components. One is a general random error and the other is an error which assumed to account for technical inefficiency in production. The method of maximum likelihood estimation (MLE) was applied to estimate parameters of the model which were then used to count the maximum level of output possible to produce by firms given a set of inputs. The technical efficiency index, expressed by TE index, $0 \leq T E$ $\leq 1$, was measured as the ratio between actual output and assumed the maximum level of output possible to produce. The results showed an average index of TE rice farming in the Sub-District of Cerbon, the District of Barito Kuala and the Sub-District of Aluh-aluh, District of Banjar was 0.87 indicating the performance of production was relatively good. However, there was $3.33 \%$ of all the rice farming considered technically inefficient. Such results imply that some treatments may be set to consolidate production managerial aspects in order to improve the technical efficiency of production.
\end{abstract}

\section{KEY WORDS}

Technical efficiency, stochastic frontier production function, rice, farming.

Efficiency becomes a measure to express the right or appropriate process to do or produce something by not wasting time, effort, and costs. By not "wasting" means the resources of time, energy, and costs are managed to be devoted to as little as possible. Farell (1957: 254$255)$ separates the efficiency into two components, namely technical efficiency and price efficiency. Technical efficiency reflects the ability of the effort unit to get the maximum output from the input group used; while price efficiency (or allocative efficiency) reflects the ability to manage the use of input in an optimal proportion by taking into account input and output prices and production technology. When both technical efficiency and price efficiency are fulfilled, it can be said as economically efficient (Coelli et al (2005: 51)) or, by using the term of Farell (1957: 255), i.e overall efficiency.

To measure the technical efficiency above, Farrel (1957) proposed an input-oriented idea through the unit-isoquant concept (Figure 1). Unit-isoquant which was defined as the ratio of input-per-output-unit, reflected the use of "the most efficient" inputs to produce output (Battese, 1992: 186). Each point contained in the isoquant was the output produced by an efficient effort unit on the input groups $\left(X_{1}\right.$ and $\left.X_{2}\right)$ used. There was no observation ratio value in the input-per-output-unit space which exceeded the unit isoquant limit located between the unit isoquant and the reference point 0 . The input-per-output-unit ratio was only located on the unit isoquant or deviated from the unit isoquant and was located in the space outside the isoquant unit. The production activities that had a ratio of input-per-output-unit ratio that deviated from this isoquant unit, for example at point $P$, were seen as technically inefficient because to produce per isoquant unit, it required a relatively larger quantity of input 
groups rather than needed when producing at point $Q$. The size of the technical inefficiency at point $\mathrm{P}$ is measured relatively as $\frac{\mathrm{OP}}{\mathrm{OQ}}$ ratio, with $\frac{\mathrm{OP}}{\mathrm{OQ}}<1$.

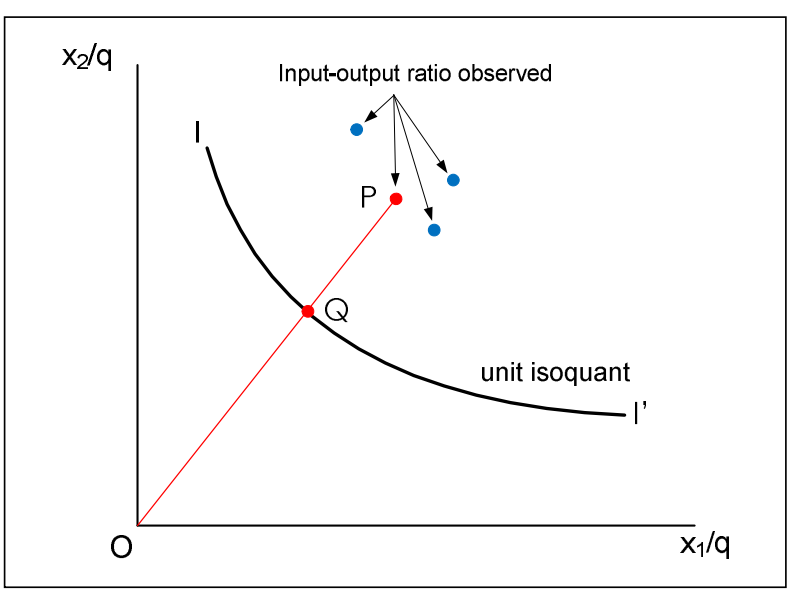

Figure 1 - Technical efficiency at point $Q$ was measured in the concept of isoquant units (adapted from Farell (1957: 254), Battese (1992: 186), and Coelli et al (2005: 52)

The concept of Farell's unit isoquant technical efficiency above was elaborated by Battese (1992: 187) with an output-oriented approach using frontier production functions. The output-oriented approach focused on measuring the efficiency of achieving the maximum level of output that may be produced at a certain quantity level from input groups and the production technology used. Effort unit production activities were encouraged proportionally to produce maximum output at a certain level of technology without the need to change the number of input groups used (Coelli, et al (2005: 54 and 67)). The frontier production function, in this sense, was defined in terms of maximum output that can be produced from a certain measure of input clusters at the level of available technology (Battese (1992)), Chambers (1988) and Yotopoulus \& Nugent (1976).

The production function, thus, showed the intended technical efficiency. The failure of the production performance of an effort unit to produce output as indicated by the frontier production function at a certain level of input clusters indicated a technical inefficiency.

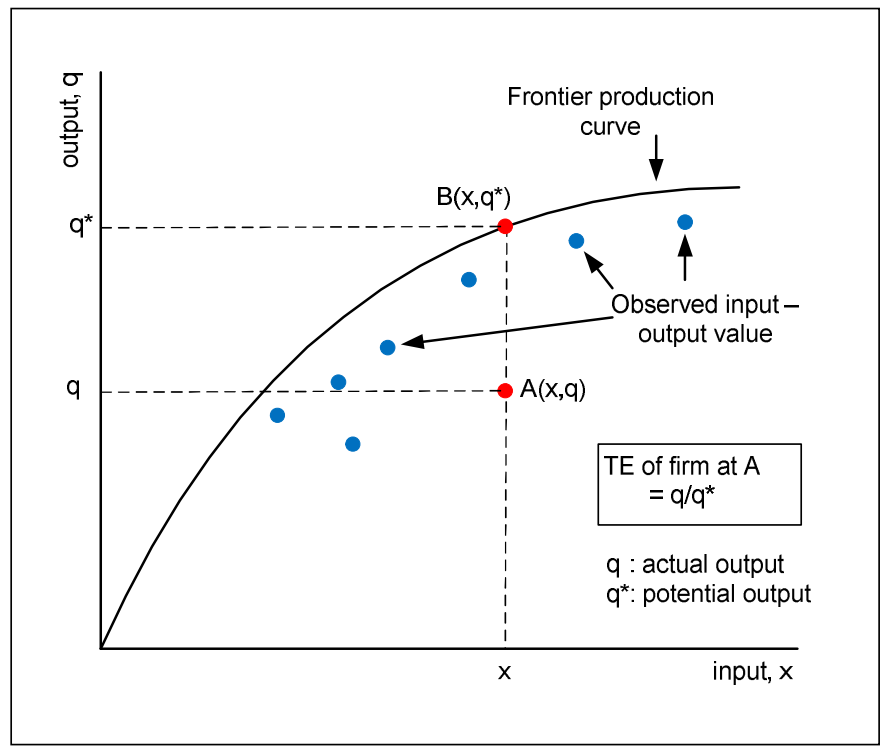

Figure $2-$ Technical inefficiency at production point $A$ was $\frac{q}{q^{*}}<1$ because the quantity of output produced was lower than the potential output (adapted from Battese (1992: 187) 
The size of the technical unit inefficiency was expressed relatively as a ratio of the actual output to the potential maximum output (Figure 2) and denoted as $\frac{\mathrm{q}}{\mathrm{q}^{*}}$, where $\mathrm{q}$ is the quantity of actual output and $\mathrm{q}^{*}$ is the potential output quantity. The technical inefficiency of the effort unit is shown by $\frac{\mathrm{q}}{\mathrm{q}^{*}}<1$.

The measurement of the technical efficiency of rice farming has an important position, especially if it is used as an evaluation of the production performance of the farm and as the input and consideration for future improvements. Moreover, this rice farming was located in the location of tidal swamp wetlands. Because of its biophysical characteristics that were always saturated or waterlogged by the shallow water throughout the year or for a long time in a year (Subagyo, 2005: 1) caused by the influence of tidal floods (Noor, 2007: 4-5) made tidal swamp land became not optimal or had low fertility for plant growth. There were 121,864 hectares of tidal swamp land in South Borneo, most of which were located in Barito Kuala District $(76,811$ hectares) and in Banjar District (29,953 hectares) (Hamdani, 2014: 30).

To make it capable of producing maximum output quantities, sub-optimal lands with a number of natural constraints and specific limitations need to be improved through engineering and advanced technology and managerial capabilities to allocate proportional input use. Muller (1974: 731) in Battese (1992: 187) revealed that one source of technical inefficiency in effort units in production was derived from the role of non-physical inputs, especially information or knowledge that affects the ability of effort units to use technology that is available thoroughly. Amodu (2011) identified education, farming experience, and family size were the non-physical factors that had a significant effect on the inefficiency of effort unit managerial to allocate the use of input to achieve the maximum output levels.

This study was aimed to identify the factors of production that influence the performance of production technical efficiency in lowland rice farming in Cerbon Subdistrict, Barito Kuala District and Aluh-aluh Subdistrict in Banjar District, as well as to plot the existence of rice farming based on the technical efficiency performance.

\section{METHODS OF RESEARCH}

This study was conducted in Cerbon Subdistrict, Barito Kuala District and in Aluh-aluh Subdistrict, Banjar District - South Borneo. These sub-districts were determined based on the consideration that the production of rice in both sub-districts was large.

Stochastic Frontier Production Function was specified as a Cobb-Douglas production function:

$$
q=\beta_{0} \prod_{i=1}^{7} x_{i}^{\beta_{i}} e^{(v-u)}
$$

To make (eq. 1) linear so that the regression estimation can be carried out, a log-linear monotonic transformation was done:

$$
\ln q=\ln \beta_{0}+\sum_{i=1}^{7} \beta_{i} \ln x_{i}+(v-u)
$$

Where: $q$ is the quantity of milled dry paddy produced $(\mathrm{kg}) ; \mathrm{x}_{1}$ is planting land (hectares); $\mathrm{x}_{2}$ is number of seeds $(\mathrm{kg})$; $x_{3}$ is number of limestones $(\mathrm{kg})$; $x_{4}$ is number of chemical fertilizer $(\mathrm{kg})$; $x_{5}$ is number of family labour (manday work); $x_{6}$ is number of hired labour (manday work); $x_{7}$ is number of drugs: insecticides and fungicide $(\mathrm{L}) ; \mathrm{v}-\mathrm{u}$ is error terms consisting of random error, $\mathrm{v}$ which is assumed to be free and identical distribution following the normal distribution $\mathrm{v}$ $\mathrm{N}\left(0, \sigma_{v}{ }^{2}\right)$; and one-side error, $\mathrm{u}$ whose existence is associated with technical inefficiencies, 
assumed to spread following a half-normal distribution, denoted as $\mathrm{u} \sim\left|\mathrm{N}\left(0, \sigma_{\mathrm{u}}\right)\right|$ (Jondrow et al, 1982: 233-234).

The size of $\beta_{i}$ for each input $x_{i}$ used was the production elasticity, $E_{p}$ from the input that was interpreted as a percentage response to the change in output produced if the quantity of input used was changed (or raised) by 1 percent. The $\beta_{i}$ size also identified the quantity allocation of input use whether it was in an economically-feasible region of production or not (Coelli, 2005: 13). If an input has a production elasticity, $E_{p}$ with $0<E p<1$, then it could be said that the input has been allocated economically-feasible.

Stochastic frontier production function (2) was estimated using MLE (Maximum Likelihood Estimation) procedure using Frontier 4.1 program. Tests on the results of the estimation are carried out by t-test.

The technical coefficient index was calculated from the following:

$$
\mathrm{TE}=\frac{\beta_{0} \prod_{\mathrm{i}=1}^{\mathrm{k}} \mathrm{x}_{\mathrm{i}}^{\beta_{\mathrm{i}}} \mathrm{e}^{(\mathrm{v}-\mathrm{u})}}{\beta_{0} \prod_{\mathrm{i}=1}^{\mathrm{k}} \mathrm{x}_{\mathrm{i}}^{\beta_{\mathrm{i}}} \mathrm{e}^{\mathrm{v}}}=\frac{\mathrm{q}}{\mathrm{q}^{*}}, 0 \leq \mathrm{TE} \leq 1(3)
$$

Where: $q$ is actual output; and $\mathrm{q}^{*}$ is potential output.

Using Collie's Frontier 4.1 programme, the $\beta_{i}$ estimator was found along with the parameter estimator: $\sigma_{\varepsilon}^{2}=\sigma_{v}^{2}+\sigma_{u}^{2}$ (denoted as sigma square), $y=\frac{\sigma_{u}^{2}}{\sigma_{\varepsilon}^{2}}=\frac{\sigma^{2}{ }_{u}}{\left(\sigma^{2}{ }_{v}+\sigma_{u}^{2}\right)}$ (denoted as gamma), and the value of TE where $0 \leq \mathrm{TE} \leq 1$. Parameter estimator $\mathrm{y}$ stated the large share of various technical inefficiency errors in the overall error range. The LR (loglikelihood ratio) test was performed on the hypothesis $\mathrm{H}_{0}: \mathrm{y}=0$ which specified that there was no form of technical inefficiency in the model. Test statistics: $\lambda=2\left[\ln \left\{L\left(\mathrm{H}_{0}\right)\right\}-\ln \left(\left\{L\left(\mathrm{H}_{1}\right)\right\}\right]\right.$ with $L\left(\mathrm{H}_{0}\right)$ and $L\left(\mathrm{H}_{1}\right)$ were the values of the likelihood function in the null hypothesis, $H_{0}$ and at the alternative hypothesis, $H_{1}$ respectively. At the position of the hypothesis $H_{0}: Y=0$, the statistics $\lambda$ distributed close to the $X(1-2 \alpha, \mathrm{df}=1)^{2}$ distribution.

\section{RESULTS AND DISCUSSION}

Estimating Stochastic Frontier Production Function. The results of the MLE estimation of the frontier production function (2) are shown in Table 1.

Table 1 - MLE estimation results on frontier production functions

\begin{tabular}{llllc} 
& & Coefficient & Standard error & t-ratio \\
\hline & beta 0 & $0.3276 \mathrm{E}+01$ & $0.4194 \mathrm{E}+00$ & $0.7812 \mathrm{E}+01$ \\
Land & beta 1 & $0.8082 \mathrm{E}+00$ & $0.1066 \mathrm{E}+00$ & $0.7585 \mathrm{E}+01^{1}$ \\
Seed & beta 2 & $-0.4789 \mathrm{E}-01$ & $0.5681 \mathrm{E}-01$ & $-0.8429 \mathrm{E}+00^{\text {ns }}$ \\
Limestone & beta 3 & $0.7285 \mathrm{E}-01$ & $0.4488 \mathrm{E}-01$ & $0.1623 \mathrm{E}+01^{3}$ \\
Chem. fertilizer & beta 4 & $0.2072 \mathrm{E}-01$ & $0.8396 \mathrm{E}-01$ & $0.2468 \mathrm{E}+00^{\text {ns }}$ \\
Family labour & beta 5 & $0.2866 \mathrm{E}-01$ & $0.4161 \mathrm{E}-01$ & $0.6886 \mathrm{E}+00^{\text {ns }}$ \\
Hire labour & beta 6 & $0.2206 \mathrm{E}+00$ & $0.9486 \mathrm{E}-01$ & $0.2325 \mathrm{E}+01^{2}$ \\
Drugs & beta 7 & $0.5800 \mathrm{E}-01$ & $0.4125 \mathrm{E}-01$ & $0.1406 \mathrm{E}+01^{4}$ \\
\hline
\end{tabular}

$\log$ likelihood function $=0.1178 \mathrm{E}+02$

LR test of the one-sided error $=0.465 \mathrm{E}+01^{5}$

with number of restrictions $=1$

Note:

$1 \quad$ Significance level $\alpha=0.010, \mathrm{t}_{0.005}(\mathrm{df}=52)=2.6737$

2 Significance level $\alpha=0.050, \mathrm{t}_{0.025}(\mathrm{df}=52)=2.0066$

Significance level $\alpha=0.115, \mathrm{t}_{0.057}(\mathrm{df}=52)=1.6029$

Significance level $\alpha=0.179, \quad \mathrm{t}_{0.085}(\mathrm{df}=52)=1.3980$

Significance level $\alpha=0.070, \quad \chi^{2} 0.965(\mathrm{df}=1)=4.4 .4452$

ns not significant 
The results of statistical testing by referring to the t-ratio of each coefficient of production input showed that the production input as follows: land (at significant level, $\alpha=$ $0.01)$, hired labour $(\alpha=0.05)$, limestone $(\alpha=0.115)$, and drugs $(\alpha=0.179)$ had an effect on the yield of milled dry grain produced. Meanwhile, the input of seeds, chemical fertilizers, and family from the results of the testing, was declared to have no significant effect.

The size of the coefficient on regression estimation of stochastic frontier production function (2) in Table 1 was defined as the production elasticity, $E_{p}$ of each production input, namely the percentage effect of each input if it was changed by $1 \%$ to the percentage change in output. The coefficient value of $0.8082 \mathrm{E}+00$ on the land factor, for example, means that if the area of paddy field used for rice farming is increased by $1 \%$, then the resulting output of dry milled grain will increase by $0.81 \%$.

The size and sign of the production elasticity characterized whether production inputs had been allocated economically-feasible or not. If it has $0<E p<1$, then the quantity of the input was said to have been allocated economically feasible. The input quantity provided was at stage II of the neoclassical production function. According to Chambers (1988: 9), the quantity of input given at stage II met the properties as follows: nonnegativity, weak essentiality, non-decreasing in $\underline{\mathrm{x}}$ (or monotonicity), and concave in $\underline{\mathrm{x}}$, with $\underline{\mathrm{x}}$ was the input vector used in production.

Concave in $x$ or the curvature of the production function in a concave form to the input variables $x$ implied that the marginal product of all inputs was non-increasing which was known as the law of diminishing marginal productivity. Included in the criteria was the number of such input doses, namely land, limestone, chemical fertilizer, family labour, hired labour, and drugs.

If $E_{p}<0$ (negative) meaning that the quantity of input given at stage III of the neoclassical production function, it was said that the allocation of the use of production inputs related to it violates the monotonicity property (Coelli, et al, 2005: 14). The amount of use of input in production activities at this position was overutilized. Each addition per unit of input, the resulting output will decrease. In the lowland rice farming activity studied, seeds were the production input which considered as excessively use compared to what was needed economically.

Technical Efficiency Index. The existence of technical inefficiencies in farming production activities as represented by the error in the function equation of stochastic frontier production (2) was indicated by the results of a significant LR statistical test $\alpha=0.070\left(\chi_{1}^{2}\right.$ $\alpha / 2(\mathrm{df}=1)=\chi_{0.965(\mathrm{df}=1)}^{2}=4.4452$ so $\left.\chi_{\text {count }}^{2}=4.651>\chi_{0.969(\mathrm{df}=1)}^{2}\right)($ Table 1$)$. The intensity of the inefficiency in each farm was indicated by the technical efficiency index. Technical efficiency index, TE was calculated as the ratio between the quantity of actual output produced by farming and the estimator value of its frontier potential output (eq. 3) as shown in Table 2.

Table 2 - Estimating technical efficiency index, TE

\begin{tabular}{|c|c|c|c|c|c|}
\hline & eff.-est., TE & & eff.-est., TE & firm & eff.-est., TE \\
\hline 1 & $0.92109109 \mathrm{E}+00$ & 21 & $0.87764176 \mathrm{E}+00$ & 41 & $0.63483538 E+00$ \\
\hline 2 & $0.82671180 \mathrm{E}+00$ & 22 & $0.90653686 \mathrm{E}+00$ & 42 & $0.89858975 \mathrm{E}+00$ \\
\hline 3 & $0.86982556 \mathrm{E}+00$ & 23 & $0.87104592 \mathrm{E}+00$ & 43 & $0.86402138 \mathrm{E}+00$ \\
\hline 4 & $0.90437711 \mathrm{E}+00$ & 24 & $0.86129502 E+00$ & 44 & $0.87977982 E+00$ \\
\hline 5 & $0.88829478 E+00$ & 25 & $0.88658280 E+00$ & 45 & $0.81908363 E+00$ \\
\hline 6 & $0.83161372 \mathrm{E}+00$ & 26 & $0.91554369 \mathrm{E}+00$ & 46 & $0.85829689 E+00$ \\
\hline 7 & $0.93793184 \mathrm{E}+00$ & 27 & $0.94685634 \mathrm{E}+00$ & 47 & $0.89320098 \mathrm{E}+00$ \\
\hline 8 & $0.91042893 E+00$ & 28 & $0.90434305 E+00$ & 48 & $0.83463793 E+00$ \\
\hline 9 & $0.90714441 \mathrm{E}+00$ & 29 & $0.91545590 \mathrm{E}+00$ & 49 & $0.90393801 \mathrm{E}+00$ \\
\hline 10 & $0.87247703 E+00$ & 30 & $0.87490899 \mathrm{E}+00$ & 50 & $0.86129726 \mathrm{E}+00$ \\
\hline 11 & $0.87571130 \mathrm{E}+00$ & 31 & $0.85409107 \mathrm{E}+00$ & 51 & $0.92331710 \mathrm{E}+00$ \\
\hline 12 & $0.81846054 \mathrm{E}+00$ & 32 & $0.94895567 \mathrm{E}+00$ & 52 & $0.84323516 \mathrm{E}+00$ \\
\hline 13 & $0.86358310 E+00$ & 33 & $0.87862593 E+00$ & 53 & $0.83860082 E+00$ \\
\hline 14 & $0.85653148 \mathrm{E}+00$ & 34 & $0.85178106 \mathrm{E}+00$ & 54 & $0.89812735 E+00$ \\
\hline 15 & $0.89831013 E+00$ & 35 & $0.92672537 \mathrm{E}+00$ & 55 & $0.84723254 \mathrm{E}+00$ \\
\hline 16 & $0.88419122 \mathrm{E}+00$ & 36 & $0.92505011 \mathrm{E}+00$ & 56 & $0.86046982 E+00$ \\
\hline 17 & $0.91066415 E+00$ & 37 & $0.89154799 E+00$ & 57 & $0.80503981 \mathrm{E}+00$ \\
\hline 18 & $0.93145062 \mathrm{E}+00$ & 38 & $0.85112898 \mathrm{E}+00$ & 58 & $0.80809716 \mathrm{E}+00$ \\
\hline 19 & $0.78726296 \mathrm{E}+00$ & 39 & $0.85411086 \mathrm{E}+00$ & 59 & $0.93327122 \mathrm{E}+00$ \\
\hline 20 & $0.87804240 \mathrm{E}+00$ & 40 & $0.89111353 E+00$ & 60 & $0.88806826 \mathrm{E}+00$ \\
\hline
\end{tabular}


The calculation results showed the average index of the technical efficiency of rice farming was 0.875 , which means that it was technically efficient. However, from all the farming examples observed, $3.3 \%$ had a low index, TE $<0.8$ or technically inefficient; $66.67 \%$ had $0.8 \leq \mathrm{TE}<0.9$; and the remaining $30.00 \%$ have TE had 0.9 (Figure 3 ). The average technical efficiency index, TE of 0.875 was higher than the results of the BravoUreta \& Pinheiro (1993) compilation of 30 studies related to the efficiency at the level of farming which was generally dominated by rice that had been carried out in 14 countries which concluded the average technical efficiency index ranged about 0.72 .

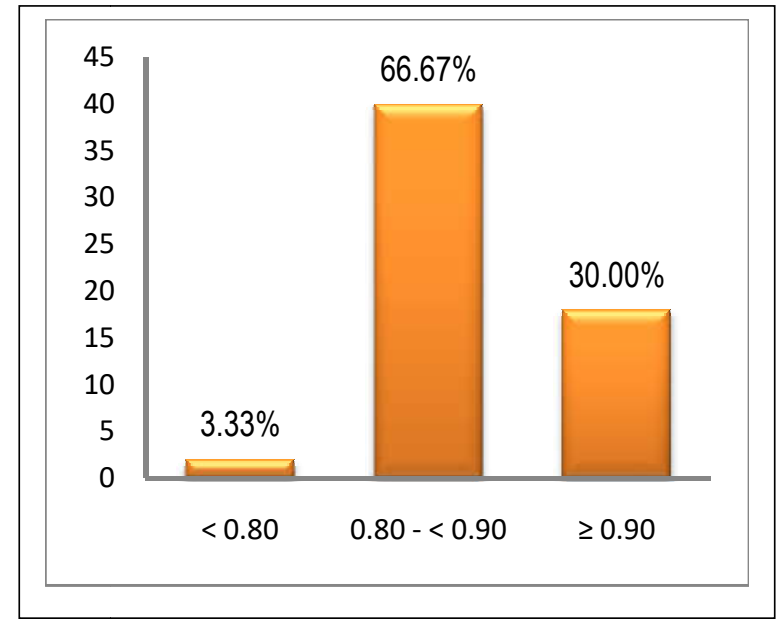

Figure 3 - Distribution of technical efficiency in rice farming

\section{CONCLUSION}

From the results of the study, it can be concluded that:

- Production inputs that had a significant effect on the level of the frontier output of wetland rice farming, namely land, limestone, hired labour, and drugs. Seed, although not statistically significant, but had a negative production elasticity indicated overutilized allocation so that it should be reduced;

- The average TE index of wetland rice farming was 0.875 or classified as technically efficient. However, among them, there were $3.33 \%$ of farms that were technically inefficient. For this farming, managerial improvement of input allocation was needed to be done, especially the one that related to seed input which indicated excessive allocation of use, as well as inputs that had a large elasticity value such as land and hired labour because the impact of changes to the input allocation has a relatively large effect on production compared to other inputs.

\section{REFERENCES}

1. Aigner, D., Lovell, C.A.K. \& Schmidt, P. (1977). Formulation and estimation of stochastic frontier production function models. Journal of Econometrics 6:21-37.

2. Amodu, M.Y., Owolabi, J.O, \& Adeola, S.S. 2011. Resource use efficiency in part-time food crop production: the Stochastic Frontier Approach. Nigerian Journal of Basic and Applied Science, 19(1):102-110.

3. Battese, G.E. (1992). Frontier production function and technical efficiency: a survey of empirical application in agricultural economics. Agricultural Economics 7:185-208.

4. Bravo-Ureta, B.E. \& Pinheiro, A.E. (1993). Efficiency analysis of developing country agriculture: a review of the frontier function literature. Agricultural and Resource Economics Review 22(1):88-101.

5. Chamber, R.G. (1988). Applied Production Analysis. A dual approach. Cambridge: Cambridge University Press. 
6. Collie, T.J., Rao, D.S.P., O'Donnell, C.J. \& Battese, G.E. (2005). An Introduction to Efficiency and Productivity Analysis. Ed. ke-2. New York: Springer Science + Business Media, Inc.

7. Collie, T.J. (1996). A guide to FRONTIER Version 4.1: a computer program for stochastic frontier production and cost function estimation. CEPA Working Papers. Department of Economtrics, UNE, Australia.

8. Farrell, M.J. (1957). The measurement of productive efficiency. Journal of the Royal Statistical Society, Series A (General) 120(3):253-290.

9. Jondrow, J., Lovell, C.A.K., Materov, I.S. \& Schmidt, P. (1982). On the estimation of technical inefficiency in the stochastic frontier production function model. Journal of Econometrics 19:233-238.

10. Meeusen \& van den Broeck. (1977). Efficiency estimation from Cobb-Douglass production function with composed error. International Economic Review 18(2): 435-444.

11. Schmidt, P. \& Lovell, C.A.K. 1979. Estimating technical and allocative inefficiency relative to stochastic production and cost frontiers. Journal of Econometrics 9:343-366.

12. Yotopoulus, P. A. \& Nugent, J. B. 1976. Economics of Development: Emperical Investigations. New York: Harper \& Row Publishers. 